\title{
LA COSA QUE PIENSA: UNA LECTURA DE LAS MEDITACIONES METAFÍSICAS DE DESCARTES ${ }^{1}$
}

Sergio Rojas

Universidad de Chile

sergiorojas_s21@yahoo.com.ar

\begin{abstract}
RESUMEN / ABSTRACT
Las Meditaciones Metafisicas de Descartes constituyen una narración. El ego opera en ésta como un recurso filosófico, en un itinerario reflexivo que se ha propuesto la conquista de un pensamiento cuya evidencia pueda ser considerada como fundamento de todo conocimiento. Esa evidencia es la existencia pensante del yo, evidencia en cierto modo predispuesta por la forma en que se la ha buscado, dándose como inicio la propia circunstancia mundana del yo que medita por escrito.
\end{abstract}

Palabras clave: Descartes, meditación, ego, Dios, existencia, pensamiento.

\section{The Thinking Thing: ON Descartes'Metaphysical Meditations}

The Metaphysical Meditations of Descartes constitutes a narrative. The ego operates as a philosophical resource trough a meditative itinerary to conquer knowledge, as well as its epistemic foundations. The self represents evidence of a knowledge shaped by the ways in which is reached, beginning by the meditative and mundane ego that writes.

KEYWords: Descartes, Meditation, Ego, God, Existence, Thought.

El sujeto moderno no surge en contacto inmediato con el mundo, sino en una apartada habitación en la que el pensador está solo consigo mismo

Christa y Peter Bürger $(2001,37)$

RA

En nuestra lectura de las Meditaciones de Descartes, nos interesa prestar especial atención al itinerario reflexivo del yo, que se desplaza desde la situación concreta en la que se encuentra el filósofo cuando inicia el proceso, hacia el ámbito de la subjetividad fundante, el que será inaugurado por la operación misma de la meditación

Este texto forma parte del Proyecto Fondecyt "La ficción del sujeto: el agotamiento del cogito en la escritura de Samuel Beckett" (n 1151049). 
como forma de la reflexión filosófica. Es decir, se trata de pensar la reflexión filosófica como algo que le sucede al yo, o, más precisamente, algo que el yo se hace a sí mismo, por cuanto lo distintivo de la filosofía sería antes que un determinado "tema" o contenido, la forma en que se dispone quien filosofa respecto a la experiencia del mundo. Darse la propia disposición subjetiva como punto de partida e ingreso en el ámbito filosófico será lo distintivo de la filosofía moderna del sujeto.

Lo anterior implica que dicha disposición no está simplemente dada para generarse la reflexión a partir de ella, sino que es necesario producirla. Porque ésta no es un sentimiento ni un afecto, tampoco una inquietud provocada directamente por algún acontecimiento mundano, sino que es producto de una operación que el individuo que reflexiona lleva a cabo sobre sí mismo. Es decir, el sujeto ha de conducirse él mismo hacia el punto inicial de la reflexión filosófica. Este es el sentido de lo que cabe denominar aquí "meditación".

\section{Retirándose desde la inmediatez del mundo}

En el inicio del texto de las Meditaciones, llama la atención la referencia explícitamente biográfica de Descartes a su circunstancia presente, cuando se trata de determinar la pertinencia de su propósito: "me era preciso intentar seriamente, una vez en mi vida, deshacerme de todas las opiniones que hasta entonces había creído y empezar enteramente de nuevo desde los fundamentos si quería establecer algo firme y constante en las ciencias" (Descartes 1980, VII, $17 / 216)^{2}$. Este pasaje inscribe la reflexión filosófica en la vida de quien reflexiona, como algo que el individuo hace consigo mismo. El lugar del yo queda así señalado como fundamental para el ejercicio filosófico, incluso del yo empírico, personal, biográfico, es decir, el yo que tiene -que ha tenido hasta ese momento- una vida "no filosófica" 3 . El ejercicio de "deshacerse de todas las opiniones" hasta ahora creídas es una forma de conducirse el pensamiento hacia el yo, estableciendo de un modo en cierto sentido a priori que el yo-debido precisamente a que se lo considera como el sujeto del pensamiento- se encuentra "detrás" de esas opiniones. Más precisamente: el propósito de deshacerse de todas las opiniones supone en su misma formulación el lugar del yo, el que quedará desprovisto de todo saber y que necesariamente habrá de sobrevivir a esa pérdida, porque ha sido desde siempre trascendente al contenido de

2 Las citas corresponden a la traducción de Ezequiel de Olaso y Tomás Zwank (1980). La referencia a las obras completas de Descartes ha sido corregida de acuerdo a la edición de Oeuvres de Descartes, de Charles Adam y Paul Tannery, señaladas en la traducción de Jorge Aurelio Díaz (2014). Entre paréntesis se indica primero la página en la edición francesa seguida de la correspondiente a la traducción de Olaso y Zwank.

3 Esto es lo que Husserl denominó la "vía cartesiana": "todo aquel que seriamente quiera llegar a ser filósofo tiene que retraerse e sí mismo una vez en la vida e intentar, dentro de sí mismo, el derrocamiento de todas las ciencias pre-dadas y su construcción. La filosofía es un asunto enteramente personal de quien filosofa" (Husserl, 4). 
sus creencias. El yo estaría en cierto sentido separado de sí mismo por la realidad del mundo; la atención del yo, su vida yoica, está en todo momento dirigida hacia el mundo en su trascendencia ${ }^{4}$. ¿Es efectivamente la posibilidad mundana del error lo que conduce a Descartes hacia la pregunta filosófica por el fundamento? ¿O la referencia al engaño e ilusiones mundanas es solo un recurso argumental en la exposición de Descartes? Mediante esta referencia, la reflexión cartesiana se introduce en el problema con la figura de la subjetividad individual, personal, biográfica.

Ocurre como si el yo que ahora medita en primera persona quisiera retirarse del mundo, dar un paso atrás de sí mismo dirigiéndose precisamente hacia ese su "sí mismo". La escena ha sido preparada: "Ahora, pues, que mi espíritu está libre de toda clase de cuidados y que me he procurado descanso seguro en una tranquila soledad, me aplicaré seriamente y con libertad a destruir en general todas mis antiguas opiniones" (Descartes 1980, 18/216). Es como si el individuo que medita hubiese ya comenzado a retirarse del mundo ("descanso seguro en una tranquila soledad"), es lo que sugiere el relato de Descartes: la condición para comenzar el trabajo filosófico consiste en el retiro del yo empírico hacia el hogar del fuero interno. Lo que orienta la narración de Descartes es el carácter autónomo de su propósito de deshacerse de las opiniones heredadas acerca del mundo; un propósito no inducido ni impuesto por las circunstancias del mundo. La circunstancia doméstica que aquí se nos describe es parte interna de la meditación. ¿Qué importancia tiene esto para los efectos de una lectura de la filosofía de Descartes? Pues, que la distinción entre conciencia y cuerpo -la que ha llegado a ser una característica de su filosofía, a la vez que uno de sus elementos más polémicos-se encuentra ya dispuesta en el modo en que Descartes se conduce reflexivamente hacia la filosofía. La filosofía será ante todo una forma de conducirse el yo hacia sí mismo fuera del mundo. Porque no se trata solo de retirarse desde la inmediatez del mundo, sino de que ese retiro implica una dirección, hacia el yo, de lo contrario se hundiría en la nada.

\section{Imposible dudar de que siento}

El suelo de las opiniones es la creencia en la fuente de esos saberes asumidos prereflexivamente: "ya que la destrucción de los fundamentos necesariamente arrastra consigo todo el resto del edificio, atacaré, por lo pronto, los principios sobre los cuales se apoyaban mis antiguas opiniones" (Descartes 1980, 18/217). En este momento el filósofo se encuentra ya en el territorio del yo, desocupando de "contenidos" sus dominios, poniendo en cuestión toda confianza en la relación con la realidad trascendente del mundo. Ahora bien, la principal fuente de verdad de las afirmaciones contenidas en esas opiniones han sido los sentidos. En relación con esto señala Descartes: "aunque

4 Como señala Husserl, en su comentario a la Primera Meditación: "Al sentido propio de todo lo que forma parte del mundo es inherente esta trascendencia, aun cuando sólo reciba y puede recibir el sentido entero que lo define, y con él su valor de realidad, de mi experiencia" (Husserl, 69). 
los sentidos nos engañan a veces respecto de las cosas poco sensibles y muy alejadas, existen quizá muchas otras de las que no se puede razonablemente dudar, aunque las conozcamos por su intermedio: por ejemplo, que estoy aquí, sentado junto al fuego, vestido con una bata teniendo este papel en las manos y otras cosas por el estilo" (Descartes 1980, 18/217). Se hace difícil poner en cuestión la confianza en los sentidos cuando se trata de realidades muy cercanas, aquello que se ofrece al individuo aquí y ahora, como sucede con la doméstica circunstancia de la meditación. Es decir, se hace difícil pensar que esto que siento aquí y ahora sea solo una ilusión. En este punto parecieran contraponerse pensar y sentir, como si se trata de dos formas distintas de autoridad, y como si el pensar no pudiese imponerse sobre el sentir: siento porque no cabe duda de que siento. El examen de esto conduce a Descartes a establecer la distinción entre pensar y sentir, en último término entre alma y cuerpo: el hecho de la imposibilidad de separar pensar y sentir que consiste en la imposibilidad de dudar, esto es, la imposibilidad de pensar de otro modo. La "prepotencia" de los sentidos conduce hacia la potencia del pensamiento mismo, como siendo éste el lugar en donde aquella "prepotencia" acontece. En suma, la realidad de los sentidos se impone con inexplicable "prepotencia" sobre la conciencia.

Descartes considera hipotéticamente la posibilidad de que en verdad se encuentre en ese momento soñando (Descartes 1980, 19/218). ¿En qué puede consistir la fuerza de este pensamiento? ¿Cómo podría el individuo que medita llegar a convencerse de que duerme? En suma: ¿cómo podría una conjetura desplazar la fuerza de los sentidos que actúa sobre el espíritu? Tal cosa no es en sentido estricto posible, pues cuando siento que todo cuanto me rodea y se ofrece a mis sentidos es verdadero, lo que propiamente sucede es que estoy convencido de ello. Puedo estar seguro de lo que pienso o puedo estar seguro de lo que siento, pero lo que resulta decisivo para el problema que aquí se aborda -la cuestión del fundamento último de la verdad que concedo a mis opiniones sobre las cosas del mundo- es el hecho de que en cada caso mi relación con la verdad consiste en que estoy seguro. ¿Cuál es el principio rector de esta convicción?

\section{Una interioridad "fuera" del universo}

El examen de la posibilidad de que nada exista es dispuesto a partir de la cotidiana certeza de que las cosas existen. Es decir, no se pregunta simplemente si estas existen o no, sino si acaso existen las cosas que desde siempre he creído que existen. Escribe entonces Descartes:

hace mucho que tengo en mi espíritu cierta opinión, a saber, que existe un Dios que lo puede todo y por el cual he sido creado y producido tal como soy. Pues, ¿quién me podría asegurar que este Dios no ha hecho que no exista tierra ninguna, ningún cielo, ningún cuerpo extenso, ninguna figura, ninguna magnitud, ningún lugar y que, sin embargo, yo tenga las sensaciones de todas esas cosas y que todo esto me parezca existir sino como lo veo? (Descartes 1980, 21/219-220). 
Fundamental en la articulación del problema es, pues, el poder absoluto de Dios, y se pregunta implícitamente qué tan absoluto es el poder de Dios. Más precisamente: el poder de crear el universo, ¿sería inferior al poder de hacerme sentir un universo que no existe? De alguna manera la cuestión planteada comprende una contraposición entre, de un lado, el poder de crear un universo que el hombre percibe y conoce en su trascendencia y, del otro lado, el poder de crear al hombre haciéndolo vivir en un universo que no existe fuera de la ilusión. No se trata aquí, por cierto, de una inquietud religiosa o teológica, sino de una cuestión estrictamente filosófica. Si el objeto del problema fuese efectivamente Dios, entonces cabría pensar que crear a un ser capaz de percibir y conocer un universo que no existe implica de alguna manera crear ese universo, solo que en la mente de esa creatura. Pero, ¿qué necesidad habría entonces de crear materialmente el universo (en sí), si este ya se habría hecho existir en la mente de hombre? Es más, ¿cómo podríamos determinar la diferencia entre ambas creaciones del universo, en sí o en la mente del hombre? Esto nos conduce hacia lo esencial de la cuestión que aquí se examina.

Lo esencial en este punto es la creencia en la realidad trascendente del mundo, esto es, en las cosas exteriores a la mente. En efecto, Descartes hace presente la imposibilidad de abandonar la costumbre de afirmar las opiniones cuya verdad ahora quisiera suspender. ¿A qué se debe esta costumbre? Pues a la creencia en la exterioridad de las cosas del mundo. La puesta en cuestión de las opiniones heredadas comienza con la suspensión de las urgencias del mundo: "no será nunca excesiva la desconfianza que hoy demuestro, ya que ahora no es cuestión de actuar, sino solamente de meditar y de conocer" (Descartes 1980, 22/221). Y sucede que lo cognoscible es aquello que está fuera de la mente, siendo trascendente a ésta. Pero si la realidad de las cosas es algo por conocer, entonces el yo del conocimiento, aquél que se afana en el propósito de conocer, pre-existe al conocimiento del mundo, lo que implica que el yo es (ya venía siendo) con anterioridad a sus relaciones con el mundo. He aquí la figura del sujeto que parece necesario suponer respecto al conocimiento posible cuando su objeto es una realidad por entero trascendente.

Jean-Luc Nancy señala que "el supuesto o el sujeto es la misma cosa. El subjectum está supuesto, está puesto abajo, debajo, por debajo” (Nancy 2014, 14). ¿Qué necesidad es la que nos conduce a poner el sujeto? Se podría responder a esto diciendo que se trata del propósito de dar cuenta del hecho mismo del conocimiento; porque el conocimiento es algo que alguien hace, y es también algo que le sucede a alguien. Pero ¿qué es ese "alguien”? ¿Por qué decimos "alguien” y no simplemente "algo”?5 ¿Qué se quiere decir cuando se determina en general la relación de conocimiento como algo

5 La solitaria meditación del ego que filosofa es un ejercicio que posibilita simultáneamente pensar y saber qué es lo que está pensando. Así, al reflexionar a solas, el yo se hace otro, llevando sus pensamientos al plano de la enunciación como si estuviese interceptando los pensamientos de otro, dirigidos a otro que no escribe, y que acaso incluso piensa sin hablar(se): "Inventor de la voz y de su oyente y de sí mismo. Inventor de sí mismo para hacerse compañía. Déjalo estar. Habla de sí mismo como de otro. Dice, hablando de sí 
que tiene lugar entre un sujeto y un objeto y no entre dos objetos? Se interroga aquí por la índole de esa relación en la que consistiría el conocimiento. Siguiendo a Nancy, lo que entendemos habitualmente por sujeto corresponde a un ser que puede tener representaciones y propósitos referidos al mundo. Pues bien, tener representaciones y propósitos es relacionarme con las cosas del mundo, es hacer que el mundo me incumba. Pero si dicha relación tiene lugar a partir de esas representaciones y propósitos, entonces es necesario que el sujeto se relacione también con estas; es decir, que sean sus representaciones y sus propósitos; constituyen su actividad más esencial, la que consiste en tenerse a sí mismo presente. "El sujeto - escribe Nancy-que comprendemos como agente, o como portador de una representación o de una volición, es entonces lo que es para sí mismo. El 'tenerse a él mismo' o el 'ser para sí mismo' define, entonces, más latamente al sujeto así comprendido" (Nancy 2014, 20). El sujeto se constituye entonces a partir de su relación con el mundo, pues se tiene presente a sí mismo en cuanto que tiene presente sus representaciones y propósitos como propios. ¿De dónde viene entonces su supuesta anterioridad? Esto se relaciona directamente con la cuestión de si acaso podría existir el sujeto si no existiese nada más, es decir, si acaso todas sus representaciones fuesen solo ilusiones.

El sujeto se tiene presente a sí mismo cuando conoce el mundo o cuando este es objeto de su voluntad; pero en ese "tenerse presente" -diciendo, por ejemplo, "mis representaciones" o "mis objetivos"- no se relaciona propiamente consigo mismo, con esa identidad, con ese Uno que el sujeto sería por debajo de todo conocimiento, es decir, antes. Y esto debido a que la identidad del sujeto de conocimiento queda desde ya esbozada como un lugar vacio, como la relación de identidad que constituye al sujeto cuando este no ha sido alterado por la densidad del mundo, cuando no está separado de sí por sus propias representaciones ${ }^{6}$. De aquí que dicha identidad solo sea "accesible" mediante la operación de tomar distancia de estas representaciones, y es lo que sucede precisamente en el escepticismo filosófico.

\section{El "dios engañador": el pensamiento del pensamiento}

Lo anterior hace de la hipótesis cartesiana del "genio maligno" un momento fundamental para la determinación del sujeto como ego:

Supondré, pues, que existe (...) cierto genio maligno, tan astuto y engañador como poderoso, que ha empleado toda su habilidad en engañarme. Pensaré que

mismo: 'Habla de sí mismo como de otro'. Se imagina a sí mismo para hacerse compañía" (Beckett 1999, 25).

6 En relación con la figura del ego como espectador trascendental, señala Jean-Luc Marion: "Yo pienso significa siempre que el pensamiento se extasía, a partir del yo y según una distancia originaria con él mismo, en dirección a aquello que posa como su objeto; sólo en esa relación la intencionalidad hace posible la representación” (Marion, 146). 
(...) todas las cosas exteriores que vemos no son sino ilusiones y engaños de los que se / sirve para sorprender mi credulidad. Me consideraré a mí mismo como sin manos, sin ojos, sin carne, sin sangre, como falto de todo sentido, pero en la creencia falsa de tener todo esto (Descartes 1980, 22-23/221-222).

No se trata por tanto solo de engañar al yo acerca de las cosas que ve, sino fundamentalmente acerca del hecho de que puede ver cosas. No solo sería falso lo que ve, sino que es ilusorio el hecho de que ve. Quien medita ha logrado mediante la duda acceder a la esfera del yo como el taller del genio maligno; se considera a sí mismo como carente de sentidos, pero "en la creencia falsa de tener todo esto". Es decir, alguien estaría siendo engañado, y de éste el yo que medita toma distancia; se diferencia al considerarse a sí mismo como sin cuerpo, pero en la creencia de tener un cuerpo. El yo se enfrenta a sus propias representaciones, se hace plenamente consciente de que su vida consiste en hacerse representaciones del mundo exterior, y es esa misma consciencia la que lo distancia de esa exterioridad. Entonces, dado que descubre que siempre ha habido representaciones, se pregunta si acaso ha habido algo más que representaciones.

El recurso cartesiano a un "genio maligno" nos aporta algo más acerca de la naturaleza del sujeto. En lo inmediato, llama la atención su carácter casi ficcional, tratándose, sin embargo, explícitamente, de un recurso en la meditación filosófica. Este genio engañador es una ficción filosófica. ¿Por qué "filosófica”? Pues porque acontece fuera de cualquier relato, no es una creatura, no es un personaje, su existencia hipotética no tiene otra finalidad que no sea producir en el yo la ilusión de un mundo que se ofrece a los sentidos. Careciendo, pues, este genio de todo propósito, podría decirse que su propia existencia hipotética carece de sentido. ¿Acaso no es este un rasgo que es propio de la realidad considerada en sí misma? Es decir, la naturaleza efectivamente trascendente de lo que consideramos como real se sustrae en último término a la pregunta por el sentido. Habremos de volver sobre esto.

Casi al inicio de la Segunda Meditación se nos hace explícita la peculiar índole de la verdad a la que conduce la duda:

Supongo, pues, que todas las cosas que veo son falsas; me convenzo de que jamás ha existido nada de cuanto mi memoria llena de mentiras me representa; pienso que no tengo sentido alguno, creo que el cuerpo, la figura, la extensión, el movimiento y el lugar no son sino ficciones de mi espíritu. ¿Qué podrá considerarse verdadero, pues? Acaso sólo que no hay nada cierto en el mundo (Descartes 1980, 24/223).

¿Cómo podría ser verdadero que no hay nada cierto en el mundo? Lo paradójico de la cuestión enunciada consiste en que se trataría para el yo de una verdad que no conduce hacia ninguna parte. Dicho de otra manera, estaríamos ante una verdad en la que nada se devela como verdadero. Lo que se anuncia con esta conjetura, la más radical de todas -en cierto modo la más inverosímil, también la más inquietante- es la pérdida de la unidad del yo, es decir, la pérdida del yo. No se trata de que si nada existe, entonces el yo tampoco existiría. El problema es más bien que si toda representación es una ilusión, por lo tanto si en ellas el yo no lleva a cabo una apropiación de la realidad trascendente del mundo, entonces el yo como sujeto deja de ser el "supuesto" que 
subrayaba Nancy -aquello que es necesario poner "debajo"-, pues no existiría nada debajo de lo cual poner al yo. Y sucede que el yo solo puede tenerse presente a sí mismo en las representaciones que refieren -aún en el error- la existencia trascendente de las cosas. Por lo tanto, es precisamente la posibilidad del engaño lo que viene a salvar en última instancia la existencia del yo: "¿Acaso no me he convencido también de que yo no existía en absoluto? No, por cierto; yo existía, sin duda, si me he convencido, o si solamente he pensado en algo" (Descartes 1980, 25/223-224).

El genio engañador no podría producir por sus propias fuerzas el engaño mismo, pues engañarse es algo que el propio yo lleva a cabo sobre sí mismo. Así, el genio maligno requiere de un "alguien" sobre el cual ejerce su poder, un yo que se engaña y que, en ello, no tiene presente la hipotética acción de ese poderoso dios engañador. Ese yo sigue habitando en un mundo que acaso no existe, nada sabe del "genio"; mejor dicho, no sabe de esa hipótesis. Descartes ha formulado respecto a ese yo-que se deja conducir por opiniones heredadas- la hipótesis de un engaño absoluto. Ese yo (que soy también yo, el que ahora duda) no puede elaborar esta hipótesis porque en sentido estricto no sabe que piensa; no sabe que cuando siente, piensa que siente. ¿A qué se debe que Descartes quiera conservar en el itinerario de su meditación a ese yo que nunca deja de creer en la existencia de las cosas? En efecto, ese yo no puede dejar de contar con la existencia de las cosas como una especie de orden impensado del pensar mismo. Dicho más precisamente: ese yo no puede dejar de pensar. Entonces, ¿qué clase de pensamiento es ese que postula la existencia de un dios engañador? Se trata del pensamiento del pensamiento, esto es, el pensamiento que se aprehende como fruto de la propia actividad representacional del mundo: el pensamiento que piensa pensamientos. Detengámonos en la hipótesis cartesiana.

¿En qué sentido podría denominarse "engaño" a una ilusión en la que alguien habría vivido siempre? "Alguien" no deja de pensar en las cosas del mundo, alguien permanece en el mundo sin cuestionarse la existencia de las cosas que se representa y que llegarían a la mente por la vía de los sentidos. Pero ese "alguien" es el propio yo que ahora duda, aunque sabe que esta duda es un ejercicio teorético. Instalado en la figura de la reflexividad, ese "alguien" que piensa en el mundo deviene un algo que piensa, una cosa que piensa. Lo que sucede en la meditación cartesiana es que el "yo" transita entre un yo mundano (atareado en la confianza y urgencias inmediatas de las cosas del mundo) y un yo filosófico (que habiendo descubierto el ámbito de la subjetividad ejercita la duda respecto a la existencia del mundo, que la ejerce incluso para mantenerse en su descubrimiento). Descartes evidencia la existencia del yo a partir de la imposibilidad de convencerse a sí mismo de que no existe: "yo existía, sin duda, si me he convencido, o si solamente he pensado en algo". En el hecho de convencerme a mí mismo está implicada la figura del desdoblamiento en el que consiste la reflexividad.

\section{5. ¿Soy algo más que una certeza?}

Si, como afirma Husserl, en la mundanidad el yo se tiene siempre presente a sí mismo, una vez acontecida la operación cartesiana, en el relato de Descartes, el yo se retira 
desde el mundo, abandona en cierto modo su mundanidad. Entonces tampoco puede el yo que reflexiona dirigirse hacia el yo que permanece en el mundo. En consecuencia, ese yo inmerso en el mundo es algo de lo cual se habla cuando se escribe la meditación -cuando se medita por escrito-, pero él mismo no habla ni escribe, no dice que piensa. En la expresión "yo existía, sin duda, si me he convencido, o si solamente he pensado en algo", Descartes habla de sí mismo como de otro, habla de alguien que ha sido convencido, pero que no lo sabe porque para este yo la existencia no es un problema. Pero he aquí que el yo que ha alcanzado la evidencia apodíctica de su existencia no solo dispone de esa seguridad, sino que su ser parece no consistir en otra cosa que en esa evidencia: existo. Digámoslo de otra manera: yo, el que sabe que existe, existo; pero no sabe de sí otra cosa que el hecho cierto de que existe. ¿Qué clase de "subjetividad" es esta, constituida por la sola certeza de su existencia?

Descartes reflexiona aquella incertidumbre fundamental: "esta proposición: yo soy, yo existo, es necesariamente verdadera siempre que la pronuncio o que la concibo en mi espíritu. / Pero no conozco aún bastante claramente lo que soy, yo que estoy cierto de que soy; (...)" (Descartes 1980, 25/224). La evidencia de la propia existencia viene del hecho de que en cuanto que pienso, existo; pero esto no significa que "pienso que existo", con lo cual la propia existencia hubiese quedado determinada como un supuesto o una opinión. Por el contrario, a partir del hecho del pienso se infiere con certeza apodíctica la existencia del yo que piensa (como algo trascendente al pensamiento). Entonces el yo que conquista esa evidencia no es sino esa evidencia: soy una certeza y por ahora nada más. No podría decirse que "soy una cosa que piensa que existe", porque entonces eso que soy ya no sería solo pensamiento, sino algo que existe y que, además, piensa. Por el contrario, solo el pensar define por ahora al yo de esta certeza apodíctica fundante. El "inocente" recurso cartesiano al dios engañador es clave aquí para dar por descontado el hecho de que el pensamiento no tiene su origen en la propia subjetividad que reflexiona. La subjetividad no puede proponerse (comenzar a) pensar, sino que más bien le sucede al yo que piensa.

Acaso el no poder dudar de la propia existencia, esto es, no poder hacer el yo de su existencia-aunque sea hipotéticamente-algo por entero asunto del pensamiento, es la imposibilidad de pensar la existencia. Si solo soy una cosa que piensa, entonces se impone necesariamente la pregunta ¿qué soy?:

encuentro aquí que el pensamiento es un atributo que me pertenece: únicamente él no puede ser separado de mí. Yo soy, yo existo: esto es cierto; pero ¿cuánto tiempo? A saber, todo el tiempo que yo piense, pues quizá podría suceder que si yo dejara de pensar, dejaría al mismo tiempo de ser o de existir. No admito ahora nada que no sea necesariamente verdadero: yo no soy, pues, hablando con precisión, más que una cosa que piensa, es decir, un espíritu, un entendimiento o una razón, que son términos cuyo significado antes me era desconocido. Así pues, yo soy una cosa verdadera y verdaderamente existente; pero ¿qué cosa? Ya lo he dicho: una cosa que piensa. Y ¿qué más? (Descartes 1980, 27/226).

¿Cómo se define la existencia del yo del pensamiento, que pareciera no trascender el acto que define al cogito? El yo de las meditaciones no piensa que existe, sino que 
infiere su existencia al no poder engañarse (pensando que existe cuando en verdad no existiría). Pero, en sentido estricto, el yo del cogito no piensa que existe, sino que simplemente está pensando: "quizá podría suceder que si yo dejara de pensar, dejaría al mismo tiempo de ser o de existir". El yo que medita no puede pensar su noexistencia, pero en sentido estricto tampoco puede pensar su existencia. Si existir es estar pensando, mantenerse pensando, entonces la pregunta “¿qué más soy [además de una cosa que piensa]?" es precisamente la pregunta por el acaso existente que piensa; es la pregunta por el sujeto que subyace al pensamiento: ¿quién está pensando? Pero el yo que piensa, precisamente en cuanto que sujeto, se impone al pensar y, en eso, se instala debajo: "es de suyo tan evidente que soy yo el que duda, el que entiende y el que desea [en suma, el que piensa], que no es necesario añadir nada aquí para explicarlo" (Descartes 1980, 29/228).

¿Qué es pensar? Dice Descartes que es el yo ("soy yo mismo") el que recibe y conoce las cosas como por los órganos de los sentidos; es decir, soy el que percibe pensando que percibe. La referencia a la sensibilidad es por lo tanto esencial a la determinación de qué sea pensar: "Pero se me dirá -escribe Descartes- que estas apariencias son falsas y que yo duermo. Lo concedo; sin embargo, por lo menos, es muy cierto que me parece que veo, oigo y siento calor; esto no puede ser falso; y es propiamente lo que en mí se llama sentir, y esto, tomado así, precisamente no es otra cosa que pensar" (Descartes 1980, 29/228). Pensar es sentir en cuanto se entienda que sentir es parecerme a mí que siento. Esto implica que el yo que siente, es decir, que piensa que siente, es afectado por el pensamiento. El análisis del trozo de cera es fundamental respecto a la cuestión de qué sea el pensamiento mismo, allí en donde ha de diferenciarse del sentir.

Se pregunta Descartes: “¿qué es esa cera que [más allá de sus cambios] no puede ser concebida sino por el entendimiento o el espíritu?” (Descartes 1980, 24/230). Lo que no puede ser aprehendido si no es por el espíritu es precisamente el ser de la cera; y considerando que ésta muta casi completamente en la sucesión de accidentes que constituyen su aspecto, quien medita se pregunta por el ser mismo. Se interroga, pues, por la mismidad de la cera, esto es, por el hecho de que permanece la misma por debajo de los cambios: "su percepción, o bien la acción por medio de la cual se la percibe [como siendo la misma a pesar de los cambios], no es una visión, ni un tacto, ni una imaginación, / y no lo ha sido jamás, aunque antes pareciera serlo así, sino solamente una inspección del espíritu" (Descartes 1980, 31/230). No se trata solo del conocimiento de lo que es en tanto que es, sino del conocimiento que tiene lugar a partir de esa manifestación en que el espíritu aprehende lo que se manifiesta (la cera) más allá de lo sensible. Lo que se manifiesta es dado mediante los sentidos, pero trasciende su ser sensible. Entonces, ¿dónde está el objeto del conocimiento, en los sentidos o más allá de estos? Pero, por otro lado, decimos que lo conocido es precisamente algo dado a los sentidos: "decimos que vemos la misma cera si nos la presentan, y no que juzgamos que es la misma por el hecho de que tenga el mismo color y la misma figura; de donde casi concluimos que se conoce la cera por la visión de los ojos, y no únicamente por la inspección del espíritu (...)" (Descartes 1980, 32/230-231). Se encuentra aquí implícito el problema de la relación entre el espíritu y el cuerpo, entre la intelección y 
la percepción. Hasta el momento el dilema es si acaso el conocimiento es un asunto de los sentidos o del espíritu. Todo indicaría que el verdadero conocimiento es asunto del espíritu; no podría serlo de los sentidos porque estos enfrentan al yo con un universo de cosas contingentes. Entonces, ¿vemos la misma cera o más bien juzgamos que es la misma? El problema así expuesto anticipa que la pregunta por el conocimiento no estará resuelta satisfactoriamente mientras no se haya determinado la relación entre el alma y el cuerpo. En la Tercera Meditación Descartes formula la cuestión de si existe algo además del yo. La vía para desarrollar esta pregunta será la cuestión de la existencia de Dios.

\section{Dios como causa del pensamiento ininterrumpido}

Señala Descartes que existen en el yo pensamientos a los que se denomina sentimientos e imaginaciones. Ambos tipos de pensamientos se refieren a algo que es externo al sujeto y cuya existencia, por lo tanto, no se tiene aún por cierta. Entonces, es cierto que tengo pensamientos, pero ¿se trata de pensamientos ellos mismos verdaderos? Se pregunta, pues, si acaso existe algo fuera de mí, y es claro que la respuesta no vendrá por otra vía que no sea el pensamiento mismo. Dado que no es posible al espíritu "salir de sí", quien medita buscará una idea (un pensamiento) que remita a una cosa externa como su causa) cuyo objeto existente fuera de mí no pueda ser puesto en duda.

Aquel pensamiento corresponde a la idea de Dios que "contiene en sí misma más realidad objetiva que aquellas que me representan las sustancias finitas" (Descartes 1980, 40/239). Dada esa magnitud superlativa de realidad objetiva, no podría ser el yo mismo la causa de la idea de Dios, por lo tanto, Dios existe. Podría decirse que la "realidad objetiva" que corresponde a la idea de Dios consiste en la magnitud contenida en esta. Entonces ahora el problema que se plantea es el de cómo es posible a un ser finito tener entre sus pensamientos la idea de Dios, considerando el carácter desmedido de esta idea. En suma: se entiende desde ya que, dadas las propiedades de la idea de Dios (eternidad, infinitud, inmutabilidad, etcétera), esta no pudo ser causada por el yo finito que aquí medita, pero entonces ¿cómo puede un ser finito concebir dichas propiedades? La cuestión de fondo es qué significa concebir la idea de Dios.

La respuesta de Descartes al problema enunciado es que el hombre concibe la idea de Dios en cuanto concibe su propia finitud; es decir, no sería posible al hombre tener presente en todo momento su condición finita si no fuese respecto a aquellas propiedades que reconoce que corresponden a la idea de Dios: “¿cómo sería posible que yo pudiera conocer que dudo y que deseo, es decir, que me falta algo y que no soy completamente perfecto, si no tuviera en mí alguna idea de un ser más perfecto que yo, en comparación con el cual conociera los defectos de mi naturaleza?" (Descartes 1980, 46/244). Dios es en cierto sentido la medida conforme a la cual el yo "sabe" de su finitud, pero se trata de una medida absoluta, es decir, una medida que no puede ser ella misma medida; Dios es, por lo tanto, para el hombre, una medida desmedida. ¿Cómo medirse con la medida de las medidas? ¿Cómo se relaciona el hombre con esa 
medida absoluta? ¿De qué modo el hombre podría ser parte de la naturaleza de esa magnitud, por cuanto se deja medir en su propia naturaleza finita por aquella? Dicho de otro modo: ¿qué clase de naturaleza es la del hombre, que para ser concebida en su finitud requiere tomar lo desmedido como medida?

El hombre no es Dios ni lo ha simplemente imaginado, pues la idea de Dios corresponde a una cosa que existe. Sin embargo, Dios es el modo en que el hombre se relaciona consigo mismo en cuanto ser finito: "Y esto [el que la idea de Dios contiene en sí más realidad objetiva que cualquier otra] no deja de ser verdadero; aunque no comprendo el infinito (...); pues pertenece a la naturaleza del infinito que mi naturaleza que es finita y limitada, no la pueda comprender" (Descartes 1980, 46/245). Entonces la concepción de la idea de Dios consiste en la conciencia que tiene el hombre de su propia finitud; es en la relación del hombre consigo mismo que está alojada la idea de Dios. Como señala Descartes: la conciencia de la finitud pertenece a la naturaleza de lo infinito. Pero si la idea de Dios corresponde a una existencia cuya naturaleza es absolutamente desmedida, ¿es que acaso lo desmedido está alojado en la relación del hombre consigo mismo? ¿Tiene el hombre, a partir de su propia naturaleza finita, "relación" con lo desmedido? En efecto, la infinitud no es algo extraño o externo al hombre, sino que corresponde al modo en que este concibe el conocimiento: "mi conocimiento aumenta y se perfecciona paulatinamente, y no veo nada que pueda impedirle aumentar cada vez más hasta el infinito" (Descartes 1980, 46-47/246). ¿Qué significa "hasta el infinito"? Pues, que la posibilidad del conocimiento humano no tiene fin. ¿Llegaría algún día a asimilarse al conocimiento divino? De ninguna manera, debido precisamente a que su progreso se proyecta al infinito, y por lo tanto le está vedada al conocimiento la posibilidad de llegar a completarse alguna vez definitivamente. Entonces, la finitud del hombre no consiste en que la posibilidad de su conocimiento sea limitada, como si alguna vez pudiese este encontrarse con un límite más allá del cual no podría seguir progresando, sino que, por el contrario, el hombre no terminará nunca de conocer la existencia que le es dada en el tiempo. En el marco de esta cuestión, Dios es conocimiento en acto (Descartes 1980, 47/246), lo que no puede de ninguna manera ser imaginado.

La divinidad está presente en el pensamiento del hombre como una idea cuyo "objeto" no puede sino existir; sin embargo, no es posible hacerse una representación de esa idea (precisamente la que contiene más realidad objetiva de cuantas son pensables), porque ello implicaría determinarla. Ahora bien, siendo Dios la causa de mi existencia, ¿qué sentido tiene la causalidad en este caso? No se trata simplemente de una relación entre dos cosas (una de las cuales sería infinita y la otra finita), pues no se piensa con ello que Dios haya sido la causa de algo en el hombre (por ejemplo, de su facultad de pensar), sino de su existencia en tanto cosa pensante. Dios es, pues, causa de la existencia de una cosa que piensa (el yo) y por lo tanto Dios mismo ha de ser una cosa que piensa, pues de lo contrario no podría dar lo que no tiene: "puesto que soy una cosa que piensa y que poseo en mí una idea de Dios, cualquiera sea, en fin, la causa que se atribuya a mi naturaleza, es preciso confesar que parejamente [Dios] debe ser una cosa que piensa, y poseer en sí la idea de todas las perfecciones 
que atribuyo a la naturaleza divina" (Descartes 1980, 49/249). El pensamiento existe en el modo de alguien que piensa ininterrumpidamente, porque su existencia consiste en pensar. Entonces Dios como la causa de la existencia del yo, es ante todo la causa de ese pensamiento, más precisamente de ese "pienso" (cogito). En las Meditaciones decir "yo" y decir "yo pienso" es exactamente lo mismo. Ahora bien, Dios es causa de lo ininterrumpido del pensamiento. Esto determina el sentido en que Dios es causa de la existencia del hombre: "es muy claro que en esto [una cadena de causas hasta llegar a Dios] no puede haber progreso al infinito, dado que no se trata aquí de la causa que me ha producido en otro tiempo, como de la que me conserva actualmente" (Descartes 1980, 50/249). Es decir, no se pregunta por la causa que en el pasado habría dado origen al yo que ahora, en el presente, medita, sino por la causa del ser de ese yo, por cuanto existir en la forma del yo significa existir conforme a un modo de ser que consiste en pensar. La causa que conserva actualmente a esa cosa cuya existencia consiste en pensar la hace persistir en ese su modo de ser al que es inherente el yo. Debido a esto, precisa Descartes, es que la causa de la existencia de un individuo no son sus padres. Los padres han producido más bien la materia en la que se encuentra encerrada la cosa que piensa (Descartes 1980, 50/250); esto es, el cuerpo, porque la condición de cosa del espíritu en tanto se le considere, por ahora al menos, como una "cosa que piensa" no viene dada por el hecho del cuerpo. En efecto, la expresión "soy una cosa que piensa" no quiere decir en modo alguno "soy un cuerpo que piensa", ni tampoco "hay algo en mí que piensa", sino simplemente "soy algo que piensa".

El problema arriba señalado es también fundamental en relación con la pregunta por el lugar en el que se encuentra esa cosa que piensa que es el yo. Si se tratara de un "cuerpo que piensa" -una criatura en la que de pronto comienza el pensamiento, entonces la idea de Dios como causa sería externa a ese objeto, pues lo que se denomina cuerpo se refiere a un tipo de existencia que, aconteciendo en la exterioridad, limita como cosa extensa con otros objetos. En cambio, correspondiendo aquella cosa que piensa en último término al yo, la idea de Dios resulta ser interna a su creación. Es decir, el yo ha sido necesariamente creado teniendo en sí la idea de Dios (Descartes 1980, 51/250). A diferencia de lo que sucede con la res extensa, en el caso del yo se nos plantea la pregunta por el sentido del límite en aquello que es finito. Ya hemos visto que es propio del espíritu la progresión del conocimiento posible hacia lo infinito; el sentido del límite es, pues, la progresión al infinito, porque el espíritu nunca terminará de conocer. Ahora bien, a partir de lo señalado por Descartes, es esencial al pensamiento del propio yo la idea-el pensamiento- de Dios. Por momentos pareciera que el propósito de Descartes fuese la demostración formal de la existencia de Dios: "toda la fuerza del argumento que he empleado aquí para probar la existencia de Dios consiste en que reconozco que no sería posible que mi naturaleza fuera tal como es, es decir, que tuviese la idea de un Dios, si Dios no existiera verdaderamente" (Descartes 1980, 51-52/251). ¿En qué medida el pensamiento del yo comprende el pensamiento (la idea) de Dios? En nuestra lectura, la reflexión de las meditaciones ha inaugurado para la filosofía el campo de la subjetividad. Así, la incorporación de la idea de Dios en el itinerario trazado por el yo no cancela aquel campo (con la emergencia del concepto de un ser trascendente), sino 
que, por el contrario, el pensamiento que tiene a Dios como objeto abunda precisamente en aquella subjetividad considerada como la verdadera vía hacia la trascendencia ${ }^{7}$.

\section{Entre el ser y el no-ser}

Señala Descartes en la Cuarta Meditación que la idea de "un ser completo e independiente" se le presenta con claridad y distinción al considerarse a sí mismo como "una cosa incompleta y dependiente" (Descartes 1980, 53/252). Es decir, aquella idea es la medida del ser en la existencia, Dios es el ser como medida en el pensamiento del yo. Esto hace difícil determinar el carácter "claro y distinto" de la idea de Dios, por cuanto esta debiese ser en cierto modo "inconcebible". En efecto, ¿es acaso concebible el ser mismo? En Descartes la idea de un ser pleno permite definir ante todo el modo de ser del yo:

no sólo se presenta a mi pensamiento una idea real y positiva de Dios, o bien de un ser soberanamente perfecto, sino también, por así decirlo, cierta idea negativa de la nada, es decir, de lo que está infinitamente alejado de toda clase de perfección; y que soy como un medio entre Dios y la nada, es decir, que estoy situado de tal modo entre el ser soberano y el no ser (...) (Descartes 1980, 54/253).

En el pasaje citado, la existencia del yo que medita participa tanto del ser como de la nada, y lo que se caracteriza mediante aquella imagen es no solo una existencia proyectada infinitamente hacia la plenitud del ser (dado que su itinerario de conocimiento hacia el ser es infinito), sino también el hecho de que en esa misma orientación está implicada la nada. En efecto, el camino del conocimiento comprende la permanente posibilidad del error, del engaño, de lo falso. Esto significa que el hombre puede en ocasiones orientar su existencia en relación con la nada, más precisamente: puede dejarse conducir a partir de ideas en donde el ser no se encuentra, sino propiamente la nada de ser. De esta índole son las opiniones y creencias erradas. He aquí lo medular en este punto: que el hombre puede efectivamente encontrarse en el error y por lo tanto encontrarse en la nada. Esto se debe a que no es simplemente el entendimiento la causa del comportamiento en el hombre: "Pues por el entendimiento solo no afirmo ni niego nada, sino únicamente concibo las ideas de las cosas que puedo afirmar o negar" (Descartes 1980, 56/255).

¿Qué significa entonces “afirmar o negar”? ¿En qué radica la autonomía de la voluntad respecto al entendimiento? En sentido estricto, el error es fruto del ejercicio de la voluntad cuando procede indiferente al criterio de las ideas claras y distintas que pueda presentar el entendimiento. Es por la voluntad que el hombre afirma o niega, y por lo tanto habría que localizar en esta la esencial relación del hombre con la trascendencia, una relación en cierto sentido a priori, pues por la voluntad el espíritu se ha dirigido hacia el ser antes de poder juzgar adecuadamente respecto a la verdad

7 "Descartes ( ) no está inclinado hacia el conocimiento de la naturaleza divina, sino que se centra en dos objetos 'profanos' complementarios: la autoelucidación de la conciencia y el conocimiento de la naturaleza concebida como 'otro' de esta conciencia” (Schaeffer, 56). 
de las ideas. Es decir, su relación con el ser no está determinada por la verdad, y esta escisión entre el ser y la verdad se origina en la voluntad. Más adelante, Descartes afirmará que "la verdad y el ser son una misma cosa"; sin embargo, dejándose conducir por la voluntad, el espíritu puede dirigirse hacia donde el ser no se encuentra. En esto la amplitud y extensión de la voluntad se diferencian radicalmente de la infinitud del entendimiento: "Experimento que únicamente la voluntad o la libertad del libre albedrío es en mí tan grande que no concibo la idea de ninguna otra más amplia y más extensa: de modo que es ella principalmente la que me hace conocer que yo llevo la imagen y la semejanza de Dios" (Descartes 1980, 57/256). Por la voluntad, el espíritu se encontraría, pues, volcado hacia la exterioridad, lo cual implica que el espíritu no es naturalmente sujeto de la voluntad dado que ésta de suyo carece de límites, he aquí su impronta divina. Sin embargo, no se trata en sentido estricto de la infinitud en acto que se le reconoce al ser de Dios, sino que la voluntad es la ilimitación en un ser finito, aquello que empuja al espíritu a actuar aun cuando sus propósitos refieren una realidad que acaso no existe y entonces aquel "se extravía muy fácilmente, y elige el mal por el bien o lo falso por lo verdadero" (Descartes 1980, 58/258). Pero, por otro lado, la posibilidad del error es inherente a la condición finita del espíritu, esto es, al hecho de que el conocimiento depende de un entendimiento finito (creado), que debe progresar en el tiempo. Por lo tanto, es forzoso pensar que la naturaleza en principio ilimitada de la voluntad es condición de la finitud, es decir, del sentimiento del carácter limitado del entendimiento, lo que da lugar en el espíritu a la duda y la ignorancia. La relación entre el entendimiento y la voluntad es pues fundamental en la determinación de la finitud del espíritu: "siempre que contengo mi voluntad en los límites de mi conocimiento, de tal modo que no forma ningún juicio sino de las cosas que le son clara y distintamente representadas por el entendimiento, no puede ser que me engañe" (Descartes 1980, 61/261). No solo la voluntad se presenta como algo que ha de ser ingresado en los límites del entendimiento, sino que este se define por el hecho de operar como un límite para la voluntad. Dicho de otra manera, sería esencial a la finitud del entendimiento el hecho de que este sea excedido por aquello a lo que debe limitar.

Una voluntad sin relación con entendimiento alguno sería una pura nada (ni siquiera habría ocasión para el error); una voluntad y un entendimiento absolutos corresponderían a un ser pleno, es decir, a Dios. Por lo tanto, el entendimiento finito es la diferencia que da lugar al espíritu humano en el ser; es la diferencia que también permite pensar a Dios como creador: "en cierto modo el que algunas de las partes de todo el Universo no estén exentas de defectos es una perfección mucho mayor que si todas fuesen iguales" (Descartes 1980, 61/260). Pues es precisamente en cuanto finito que el entendimiento humano puede ser pensado como cosa creada, es decir, como obra de Dios: "es propio de un entendimiento creado ser finito" (Descartes 1980, 61/259). Dios no podría crear otro Dios, porque el entendimiento en este tendría que ser necesariamente finito. En consecuencia, Dios, en tanto creador solo puede ser pensado a partir de su criatura, siendo la nada aquello a lo que se expone el hombre dada la finitud de su entendimiento. La representación del yo que medita como "situado entre el ser soberano y el no ser" correspondería en sentido estricto a la relación que constituye la naturaleza misma de la subjetividad. 


\section{A modo de desenlace: un pensamiento impensable}

Señala Descartes: "me parece que la naturaleza de la voluntad, que no consiste más que en una sola cosa y cuya realidad es como indivisible, es tal que no se le podría quitar nada sin destruirla" (Descartes 1980, 60/259). Ahora bien, siendo la voluntad algo de suyo ilimitado, ¿cómo puede haber un mundo (el coto que es propio de la experiencia) para un ser dotado de voluntad? Porque dada la ilimitación de la voluntad, el ser y la nada han de tornarse en principio indiferentes entre sí; de hecho, a la voluntad misma le es en cierto modo indiferente el juicio del entendimiento respecto a lo que sea verdadero. En suma, aquello que le resulta indiferente a la voluntad es la existencia. Entonces por la voluntad de suyo ilimitada, el espíritu se dirige hacia el ser, pudiendo en eso -sin el concurso adecuado del entendimiento- hundirse en la nada; el entendimiento en su finitud habría de servir a la corrección de la voluntad, haciendo que ésta en sus propósitos se refiera mediante ideas a objetos existentes. Por el contrario, la relación de Dios con lo existente es siempre la de un creador; Dios no podría relacionarse finitamente con la existencia (esto es; proponerse cosas, percibir, experimentar, conocer, etcétera). En consecuencia, la relación de Dios con la existencia no pude ser pensada en cuanto que Dios mismo no puede ser pensado como un ser particular, una criatura, un sujeto. Ahora bien, la imposibilidad de separar a Dios de la existencia de las cosas en general (la existencia de todo cuanto existe) es la imposibilidad de separar a Dios de su propia existencia. Dicho más precisamente: no es posible siquiera preguntarse si acaso Dios existe o no, porque no es posible sino pensarlo como "existente", lo cual implica que no es posible pensarlo como "algo" (como una cosa, particular) a lo que se añada en la mente del hombre, por un razonamiento, la existencia: "la necesidad de la cosa misma, a saber, de la existencia de Dios, determina mi pensamiento a concebirlo de este modo. Pues no tengo libertad de concebir un Dios sin existencia (...), como soy libre de imaginar un caballo sin alas o con alas" (Descartes 1980, 67/266). No es posible concebir a Dios como algo sin existencia como tampoco es posible concebirlo como algo "con" existencia. En consecuencia, en último término, la idea de Dios es la idea de la existencia misma, y es esa idea, ese pensamiento, el que no puede ser separado del espíritu del yo que medita ${ }^{8}$. De aquí que podría decirse que con la idea de existencia se trata de un pensamiento que no puede ser pensado: "Y en lo que se refiere a Dios, por cierto, si mi espíritu no estuviese prevenido por algún prejuicio ni mi pensamiento se encontrase distraído por la presencia continua de las imágenes de las cosas sensibles, / no existiría nada que conociese más rápida ni más fácilmente que él" (Descartes 1980, 69/267-268). Es decir, las imágenes de las cosas sensibles, en el devenir que les es propio, provocan en el espíritu la cuestión de la existencia a propósito de los objetos que corresponderían a esas imágenes. La conciencia de las imágenes (en que las cosas se han separado de su existencia, por un momento solo posible), es la que da lugar a la pregunta por la existencia de tal o cual objeto, pero no

8 "La trascendencia es en toda forma un sentido de realidad que se constituye entro el ego" (Husserl, 141). 
es posible preguntar por la existencia misma (¿existe algo además de mí?, es decir, ¿existe algo?, ¿hay la existencia?). En esta imposibilidad consistiría la idea de Dios en el espíritu finito.

El momento constituyente de la finitud es la voluntad de suyo ilimitada en el hombre. La voluntad se confronta con la finitud "del" entendimiento, pero solo en cierto sentido, porque lo que sucede es que el entendimiento como tal no podría ser pensado sino como finito: "por el entendimiento solo no afirmo ni niego nada, sino únicamente concibo las ideas de las cosas que puedo afirmar o negar". El entendimiento no es en sí mismo "limitado", sino que opera como límite en un sujeto dotado de voluntad, hace concebible un mundo posible allí en donde el sujeto ya se orienta hacia el ser. Esta determinación da lugar a la subjetividad (con sus convicciones, dudas y errores). Un ser finito es, pues, aquel que no es en acto, sino que necesita actuar, y es así como no solo requiere del entendimiento y la voluntad, sino que su condición solo es pensable a partir de la diferencia entre entendimiento y voluntad. Esta separación misma es la finitud del entendimiento; la separación entre entendimiento y voluntad es la finitud, lo que no es concebible en Dios, que es en acto.

El modo en que Descartes concibe la existencia pensante del yo se relaciona internamente con el itinerario reflexivo que lo ha conducido hacia éste. Así, la polémica distinción entre alma y cuerpo expuesta en la Sexta Meditación no es sino la conclusión que se sigue de la naturaleza misma del cogito:

soy una cosa que piensa, o una sustancia cuya esencia o naturaleza íntegra no consiste más que en pensar. Y aunque quizá (o más bien ciertamente, como pronto diré) tenga un cuerpo al que estoy muy estrechamente unido, (...) es cierto que yo, es decir, mi alma, por la cual soy lo que soy, es entera y verdaderamente distinta de mi cuerpo y que puede ser o existir sin él (Descartes 1980, 62/276-277).

Una inferencia estrictamente filosófica, con frecuencia polemizada en territorios distantes a las condiciones filosóficas de la cuestión ${ }^{9}$. Lo que Descartes hace en las Meditaciones no es sino conducir hasta sus implicancias últimas la idea de un ego pensante, recorriendo un camino que en su relato se ha dado como inicio el propio yo de quien medita. Al cabo del proceso, ese yo va develándose como la circunstancia inicial de un pensamiento para el cual el ser está siempre en otro lugar, al que de alguna forma es necesario alcanzar ${ }^{10}$ (Bürger, 37). El pensamiento habrá de trascenderse a sí mismo para llegar a saber de aquello que no es él. Las Meditaciones de Descartes

$9 \quad$ Uno de los argumentos más conocidos en esta dirección es el del neurólogo Antonio Damasio: "Este es el error de Descartes: la separación abismal entre el cuerpo y la mente ( ). Más específicamente: que las operaciones más refinadas de la mente están separadas de la estructura y funcionamientos de un organismo biológico" (Damasio, 286).

10 "Descartes sitúa (...) la escena originaria de su pensamiento en un lugar de recogimiento: en la poele, la bien caldeada habitación del cuartel de invierno en Ulm, donde solo y sin ningún tipo de relación social se dispone a buscar una primera certeza inamovible" (Bürger, $37)$. 
constituyen la escena fundante de la filosofía moderna del sujeto, encontrando en la soledad del yo su condición de posibilidad.

\section{Referencias bibliográficas}

Beckett, Samuel (1999), Compañia. Barcelona: Anagrama.

Bürger, Christa y Peter (2001), La desaparición del sujeto. Una historia de la subjetividad desde Montaigne a Blanchot. Madrid: Akal.

Damasio, Antonio (2006), El error de Descartes. Barcelona: Debolsillo.

Descartes, René (1980), “Meditaciones Metafísicas”, Obras Escogidas, traducción de Ezequiel de Olaso y Tomás Zwanck. Buenos Aires: Charcas.

(2014), Meditaciones acerca de la Filosofía Primera. Seguidas de las objeciones y respuestas, traducción de Jorge Aurelio Díaz (edición trilingüe) Bogotá-Colombia: Universidad Nacional de Colombia.

Husserl, Edmund (1986), Meditaciones Cartesianas. México: Fondo de Cultura Económica.

(2009), Las conferencias de París. Introducción a la fenomenología trascendental. México: Instituto de Investigaciones Filosóficas de la UNAM.

Marion, Jean-Luc (2012), Cuestiones cartesianas. Buenos Aires: Prometeo.

Nancy, Jean-Luc (2014), ¿Un sujeto? Buenos Aires: La Cebra.

Schaeffer, Jean-Marie (2009), El fin de la excepción humana. Buenos Aires: Fondo de Cultura Económica. 